\title{
Sujeito, mídia e "consumo de experiência" nas celebridades juvenis: afetos e proximidade na relação da escritora Paula Pimenta com suas fãs
}

Subject, media and "consumption of experience" in celebrities to youth audience: Affections and proximity in the relationship between the writer Paula Pimenta and her fans

\author{
Marcella Azevedo \\ Cláudia Pereira ${ }^{2}$ \\ Carla Barros ${ }^{3}$
}

\begin{abstract}
Resumo: Com 18 livros publicados e mais de 1,2 milhão de exemplares vendidos, Paula Pimenta é um fenômeno de vendas do mercado editorial nacional. Tendo em vista sua expressividade como celebridade juvenil, partiu-se de um estudo de caso sobre a relação da escritora com suas fãs, que extrapola o ambiente midiático e a interação via redes sociais, configurando-se como uma relação próxima e pessoal, na qual afetos e estados de subjetividade são vivenciados na tênue fronteira entre ficção e realidade. Pretende-se investigar aspectos de "consumo de experiência" identificados nessa relação, assim como compreender o impacto desses mecanismos na constituição de identidades juvenis contemporâneas. Foram analisadas matérias publicadas na mídia sobre a autora e suas obras, assim como a interação entre Paula Pimenta e suas fãs nas redes sociais on-line.

Palavras-chave: celebridades; consumo de experiência; literatura juvenil; Paula Pimenta.
\end{abstract}

1 Pontifícia Universidade Católica do Rio de Janeiro. Rio de Janeiro, RJ, Brasil. E-mail: msazevedo@globo.com

2 Pontifícia Universidade Católica do Rio de Janeiro. Rio de Janeiro, RJ, Brasil. E-mail: claudiapereira@puc-rio.br

3 Universidade Federal Fluminense. Niterói, RJ, Brasil. E-mail: barros.carla@uol.com.br 
Abstract: With 18 published books and more than 1.2 million copies sold, Paula Pimenta is a sales phenomenon of the national publishing market. In view of her expressiveness as a celebrity to youth audience, this paper is based on a case study about the writer's relationship with her fans, which extrapolates the media environment and interaction through social networks. This has created a close and personal relationship where the affection and states of subjectivity are experienced on the tenuous border between fiction and reality. This study aims to investigate aspects of "consumption of experience" identified in this relationship, as well as to understand the impact of these social relations on the constitution of contemporary juvenile identities. Articles published in the media about the author and her books are analyzed, as well as the interaction between Paula Pimenta and her fans in online social networks.

Keywords: celebrities; consumption of experience; juvenile literature; Paula Pimenta. 
Com 18 livros publicados e mais de 1,2 milhão de exemplares vendidos, Paula Pimenta vem se consolidando como uma das principais escritoras brasileiras e tem livros lançados em diversos países. Pimenta tem status de celebridade e uma legião de fãs, em sua grande maioria meninas adolescentes que se autodenominam "as pimentinhas". Seus livros, no geral, são romances contemporâneos, muitas vezes inspirados em clássicos contos de fada, sempre com protagonistas adolescentes.

Pretende-se, a partir de um estudo de caso da escritora e ídolo juvenil Paula Pimenta, refletir sobre o fenômeno das celebridades, mais especificamente sobre sua relação com a mídia e a construção de identidades juvenis contemporâneas. Objetiva-se, ainda, analisar o "consumo de experiência", que envolve a relação da escritora com seus fãs, em que afetos e estados de subjetividade são vivenciados na tênue fronteira entre ficção e realidade.

A metodologia do presente artigo se sustenta em três bases fundamentais: no estudo de caso (YIN, 2001), na observação on-line não participante (ORGAD, 2009) e na pesquisa documental.

Para Yin (2001, p. 32), "o estudo de caso é uma investigação empírica de um fenômeno contemporâneo dentro de um contexto da vida real, sendo que os limites entre o fenômeno e o contexto não estão claramente definidos". A decisão pelo estudo de caso, seguindo os preceitos de Yin, permite, em primeiro lugar, investigar e compreender mais pontual e profundamente um fenômeno específico e, em segundo lugar, ter acesso a uma análise que leva em conta as questões propostas por este trabalho, partindo de "uma ampla variedade de evidências - documentos, artefatos, entrevistas e observações” (YIN, 2001, p. 27). Parte dessas evidências resulta da coleta sistemática de dados secundários, quais sejam, entrevistas com Paula Pimenta e matérias a seu respeito publicadas nas mídias (pesquisa documental), assim como postagens diárias em seu blog, além de suas publicações nas redes sociais on-line.

Boa parte do que foi observado se concentra na viagem que a escritora realizou com um grupo de fãs no início do ano de 2014 à cidade de Brighton, na Inglaterra. No período da viagem, realizada entre 28 de 
fevereiro e 9 de março de 2014, Paula fez postagens diárias em seu blog e manteve atualização constante de seus perfis no Facebook, Twitter e Instagram. Comentamos, em parte do artigo, postagens da escritora e de suas fãs relacionadas à viagem e coletadas através de observação on-line não participante. Vale ressaltar que a abordagem adotada no artigo rejeita uma dicotomia prévia entre os universos on-line e off-line. Como bem argumentaram Miller e Slater (2004) em seu estudo etnográfico realizado em cibercafés de Trinidad, essa contraposição não deve ser tomada como ponto de partida nem metodológico, nem analítico de pesquisa, mas sim observada em contextos culturais específicos.

\section{Celebridade, mídia e juventude}

Quando Edgar Morin publicou um texto "sério" sobre as estrelas de cinema, talvez mal pudesse imaginar que inauguraria uma discussão profícua e pertinente para as ciências sociais. Partindo dos estudos sobre o mito para apontar o lugar das estrelas de cinema na sociedade moderna, Morin se aventurou em terreno ambíguo, arenoso, "misto e confuso", como ele mesmo afirmou (MORIN, 1989, p. xi), oscilante entre a "crença e o divertimento", o "humano e o divino", o "arcaísmo e a modernidade".

Eram chamados de "estrelas" - e ainda são - atores e atrizes de cinema, principalmente, que passaram, em meados do século XX, a habitar o espaço dedicado aos ídolos, antes exclusivo da esfera do sagrado. Daí as dualidades apontadas por Morin - entre a "crença e o divertimento", o "humano e o divino", o "arcaísmo e a modernidade" - ao propor uma teoria do mito para as estrelas do cinema. Naquele contexto midiático, a relação entre os fãs e as estrelas era absolutamente impossível. Caso contrário, não teriam efetividade a "magia" e a "sedução" às quais se refere Morin.

Nos tempos atuais, a distância entre admiradores e admirados parece não mais fazer parte do espírito do tempo da modernidade contemporânea. Anthony Giddens (2002) denomina de "modernidade tardia" os dias atuais, em que tomam o lugar das instituições e ideologias os "estilos 
de vida”, ou seja, um conjunto de práticas adotadas por um indivíduo a fim de dar uma forma material à sua autoidentidade.

Essa noção de estilo de vida nos lembra muito o que Morin (1989, p. 97) demonstra ao tratar do "mimetismo" estimulado pela relação de "sonho", "identificações imaginárias”, de admiração, enfim, entre o público e suas estrelas, em que o modo como nos vestimos, falamos, andamos é o mesmo daqueles que admiramos. Todos queriam ser iguais a Greta Garbo ou James Dean, e, ao sê-lo, pareciam, de fato, todos iguais. A globalização e a disseminação da mídia eletrônica, entre outros fatores, colocam o indivíduo, na modernidade tardia, frente a frente com uma outra realidade, a de um grande número de "escolhas" (GIDDENS, 2002, p. 79), e algumas delas, possíveis, podem estar representadas, também, no estilo de vida das estrelas ou das celebridades.

Outros autores, mais recentemente, têm contribuído para uma definição do conceito de "celebridade". Para Rojek (2008, p. 12), trata-se de um fenômeno de atribuição de um status a indivíduos que causam "impacto sobre a consciência pública”: há um reconhecimento, que pode ser favorável - "glamouroso", segundo o autor - ou desfavorável - "notório”. Boorstin (2006, p. 79), por seu turno, sustenta um tom mais crítico, sublinhando um caráter vazio no mérito da celebridade que, para este autor, "é uma pessoa conhecida por ser muito conhecida". ${ }^{4}$ As celebridades funcionam como artefatos regidos por motivações mercadológicas e que operam como construtos da indústria cultural. Rojek (2008, p. 12) é categórico em relação a essa questão: "Celebridades são fabricações culturais". Revestir o produto de mito e, portanto, da magia da estrela ou do glamour da celebridade é uma estratégia cultural e mercadológica, logo racional, para envolver o consumo naquilo que Giddens (2002) chama de "estilo de vida".

Perante o público, a celebridade é poderosa. Porém, essa adoração - o culto às celebridades - é composta de relações imaginárias. Sendo assim, não só há uma enorme busca pelos produtos tradicionais lançados pelos ídolos - como livros, por exemplo; os fãs querem ir além,

4 No original: "The celebrity is a person who is known for his well-Knowness". 
desejam consumir a própria celebridade. Vem daí a busca incessante por notícias sobre a celebridade na mídia e a procura por um contato com o ídolo. Nesse sentido, a mídia desempenha um papel fundamental na relação entre as celebridades e seus fãs. Para além das telas de cinema, as celebridades encontraram espaço também nos mais diversos veículos de comunicação. Gabler (1999) lembra que é antiga a ênfase dada pelos jornais aos perfis e biografias de grandes personalidades, o que passou depois a ser complementado com a publicação de fotos das grandes estrelas. O autor afirma que a busca por informações e notícias sobre as estrelas aumentava consideravelmente a venda de jornais (GABLER, 1999, p. 141). A mesma "simbiose" foi depois estendida a revistas e à televisão.

As práticas e culturas juvenis são o espaço em que a cultura da celebridade obtém maior ressonância. Para Rojek, isso se dá em função de certa crise na instituição familiar tradicional, o que levaria os jovens a buscar outros referenciais. Sem citar a família propriamente dita, mas mencionando uma indeterminação que seria intrínseca aos adolescentes, Morin afirma que as estrelas de cinema os auxiliam na busca da personalidade: "No estágio da adolescência, surge uma mimese socializadora que contribui para a formação de uma personalidade adulta. É nessa fase que são mais eficazes as influências das estrelas de cinema" (MORIN, 1989, p. 106). Já Marcel Mauss (1974) nos revela a construção social das técnicas corporais por meio do que o antropólogo denomina de "imitação prestigiosa", ou seja, reproduzir gestos, ações, comportamentos que sejam bem-sucedidos e prestigiosos dentro de um dado grupo social. Da mesma forma, as celebridades são fonte de inspiração e imitação, principalmente para os jovens em busca de prestígio social junto a seus pares.

O conceito de "juventude" é inapreensível se a intenção é esgotá-lo com facilidade. Seja qual for a perspectiva, porém, todas parecem concordar que a juventude pressupõe a ideia de construção de identidade. Compreendendo-se a juventude como uma faixa etária entre a infância e a vida adulta ou como fenômeno social que se estende a outras faixas 
etárias (ROCHA e PEREIRA, 2009), assume-se que o "ser jovem" é um estilo de vida (GIDDENS, 2002) cujo conjunto de práticas e valores inclui a necessidade urgente de construção da identidade, tanto simbólica quanto social, assim como o estabelecimento da diferença. Para Woodward (2000), a "identidade é marcada pela diferença" e a "diferença é sustentada pela exclusão", enquanto a identidade "é marcada por meio de símbolos" e a "construção da identidade é tanto simbólica quanto social” (WOODWARD, 2000, p. 9-11).

Tal como a tecnologia, por exemplo, que exerce um papel fundamental na vida do adolescente ao permitir trocas, armazenamentos, consumos e marcações sociais (ROCHA e PEREIRA, 2009), a celebridade como fabricação cultural (ROJEK, 2009) também é parte constituinte do "espírito do tempo" da modernidade tardia, favorecida pela separação entre o espaço e o tempo, chegando simultaneamente em diferentes lugares do mundo, influenciando os projetos e as ações dos indivíduos, que adotam estilos de vida que confiram identidade e segurança ontológica (GIDDENS, 2002).

\section{Paula Pimenta: romances, contos de fada e experiências diferenciadas para as fãs}

Um dos maiores expoentes atuais da literatura de entretenimento juvenil no Brasil é a escritora Paula Pimenta, considerada um fenômeno de consumo junto ao público adolescente, tendo sido alçada à categoria de celebridade e ídolo de uma legião de fãs, que se autodenominam "pimentinhas". As histórias de Paula Pimenta são ambientadas no universo juvenil e as temáticas abordadas são aquelas comumente associadas à vivência de adolescentes das camadas médias e altas. A autora imprime um tom romântico à sua obra, que trata de histórias de amor contemporâneas, com forte inspiração nos contos de fada tradicionais. Mais do que escrever sobre princesas, Paula Pimenta se diz grande fã delas, afirma que a Disney é seu destino preferido de férias e adota ela mesma uma postura romântica e juvenil. 
A autora se projetou nacionalmente com os livros das séries Fazendo meu Filme e Minha Vida Fora de Série, que narram histórias de adolescentes que lidam com questões "próprias" da juventude nos termos de sua construção social na contemporaneidade. A relação do público com sua obra vai além da posição tradicional de leitor, como é comum na chamada "cultura participativa" contemporânea (JENKINS, 2009), na qual o fã colabora com a criação de conteúdos e a divulgação de informações. Nesse contexto de grande interação estimulado pelo surgimento das novas mídias, as fãs de Paula Pimenta sempre evidenciaram seu engajamento, procurando interferir nos processos de produção: foram elas que, ao gostarem do primeiro volume de Fazendo meu Filme, mandaram mensagens para a editora solicitando a publicação da sequência da história, impactando na decisão da empresa de editar os demais volumes.

Esse cenário, que aponta para um papel ativo do público formado por meninas adolescentes na indústria do consumo, contrasta com o apontado por Angela McRobbie e Jenny Garber (1975) quando destacaram a pouca importância dada ao papel das garotas nos grupos subculturais juvenis, assim como o fato de as mulheres, de maneira geral, constituírem uma categoria até então pouco celebrada por cientistas sociais. Ao longo do tempo, as adolescentes foram se consolidando como importante público consumidor, primeiro conquistando espaços de lazer e de representação diferenciados, chegando à mídia mainstream retratadas de maneira diversificada. Para além do consumo, quando assumem o papel de fãs, essas meninas se envolvem de maneira engajada com seus produtos midiáticos preferidos. É possível identificar nas fãs de Paula Pimenta um comportamento característico da cultura dos fã-clubes, tal como aponta Fritzsche (2004): têm conhecimento profundo sobre o assunto, estabelecem laços rituais de amizade entre si e, por vezes, “imitam” o ídolo. Para a autora, "a cultura de fã-clube proporciona a elas a oportunidade de abordar ludicamente questões de autorrepresentação, confiança e heterossexualidade, que podem, embora não necessariamente tenham que, ser utilizadas para resistência" (FRITZSCHE, 2004, p. 113). 
Para além disso, os romances da escritora são o ponto de partida também para a vivência de experiências diferenciadas pelas leitoras. No início de 2014, Paula Pimenta embarcou com 15 leitoras (com idade entre 12 e 16 anos) para um pequeno intercâmbio em Brighton, na Inglaterra. A cidade foi escolhida por ser o local do intercâmbio da protagonista Fani na série Fazendo meu Filme. O roteiro incluía visitas aos principais pontos turísticos mencionados nos livros. Nas palavras da autora, em seu blog:

[...] pude mostrar para as meninas os lugares onde o Christian e a Fani passaram em "Fazendo meu filme 2", inclusive o local onde ele a pediu em namoro! A gente entende a Fani, né? Em um lugar bonito desses não dava mesmo pra resistir! (PIMENTA, 2 mar. 2014).

Para as fãs, a viagem é uma rara oportunidade de ultrapassar a interação mediada, para a qual Rojek usa o termo "interação parassocial":

O termo "interação parassocial" é usado para se referir a relações de intimidade construídas através da mídia, e não pela experiência direta e encontros cara a cara. Essa é uma forma de intimidade de segunda categoria, visto que deriva de representações da pessoa e não de um contato físico verdadeiro (ROJEK, 2008, p. 58).

O autor afirma que esse tipo de relacionamento é, no fundo, imaginário, uma vez que sempre mediado e quase nunca no âmbito presencial. Viajando com a escritora, as leitoras estabelecem uma relação com ela que extrapola as fronteiras midiáticas, se tornando social em seu sentido mais estrito, e não mais "parassocial”, como propõe Rojek. A partir daí, essas leitoras se diferenciam, se tornam conhecidas do ídolo e o relacionamento assume laços mais íntimos que elas tomam como amizade genuína. Soma-se a isso também a possibilidade, de certa forma, de se aproximar dos personagens e das narrativas que elas tanto admiram. Ao visitar os cenários das histórias onde aconteceram algumas das principais cenas, as leitoras também "se apropriam" do universo ficcional.

Essa posição diferenciada é chancelada pela própria autora. Durante a viagem, Paula fez postagens diárias em seu blog e manteve atualizados 
seus perfis no Facebook, Twitter e Instagram. Era possível, então, ver fotos da viagem, com a escritora aparentando estar bem integrada às adolescentes. O clima de amizade pode ser conferido na postagem da escritora ao fim da viagem:

O mini-intercâmbio chegou ao fim... No momento da despedida foi a maior choradeira! Não consegui segurar as minhas lágrimas ao abraçar minhas girls!! Foram 10 dias muito intensos e neles eu pude conhecer melhor cada uma delas. Difícil agora vai ser aguentar a saudade... (PIMENTA, 9 mar. 2014).

As meninas integrantes do grupo também fizeram postagens durante a viagem, mostrando um clima de intimidade com a escritora.

Figura 1 - Print screen do blog Fazendo meu Filme. Postagem de 9 de março de 2014.

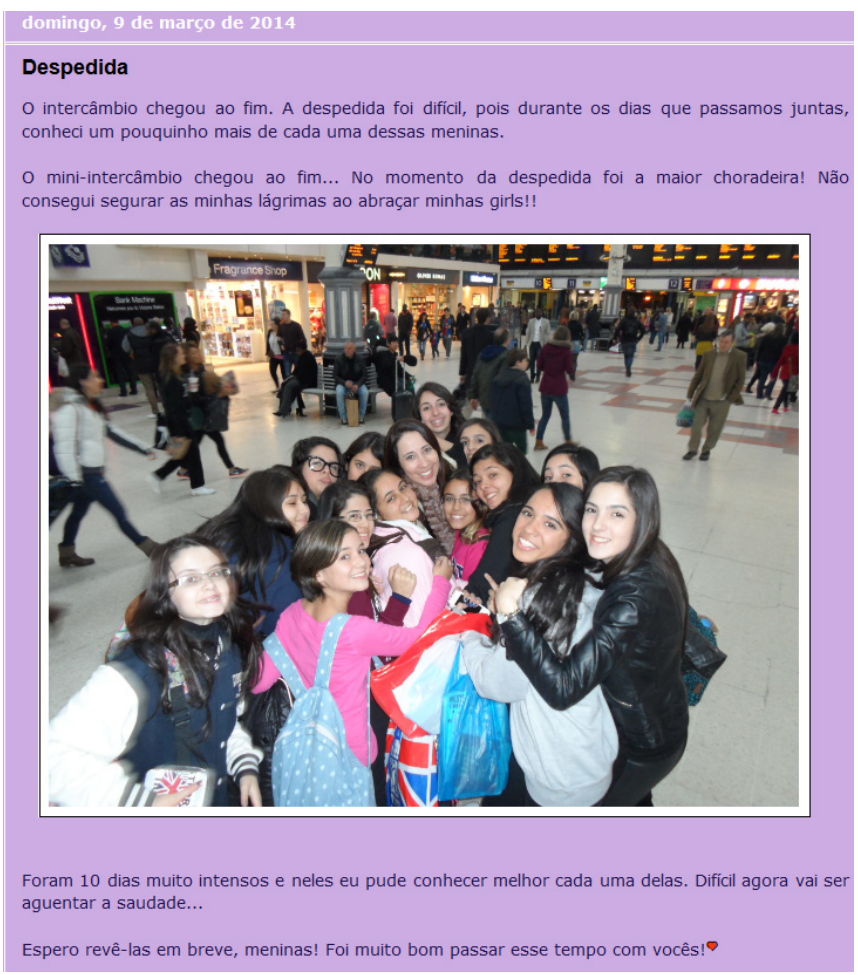

Fonte: http://blogfazendomeufilme.blogspot.com.br/2014/03/despedida.html. Acesso em: 12 jan. 2018. 
Outro intercâmbio já havia sido realizado no ano anterior, quando a escritora foi com um grupo de fãs a Vancouver, no Canadá. A relação estava no fato de o grupo estar realizando um intercâmbio de estudos, tal como a protagonista de Fazendo meu Filme. Porém, a escritora contou que aproveitou para fazer pesquisa para ao terceiro volume de Minha Vida Fora de Série.

Vale ressaltar ainda que as viagens de Paula Pimenta com suas leitoras, em especial aos locais que servem de cenário para suas narrativas ficcionais, podem ser relacionadas aos estudos de peregrinação de fãs. Tal como explica Mascarenhas (2017), ao retomar o termo estudado por Roger Aiden em 1999:

O fenômeno envolve um deslocamento do indivíduo no espaço e no tempo, seja através de uma viagem interna do fã consumidor ao ler uma ficção ou de uma viagem física. Estes espaços físicos rememoram produtos, tais como sets de filmagem, a casa de infância onde morava um ídolo, lápides de personalidades mortas. Também são consideradas peregrinações trajetos trilhados pelos fãs para ver ao vivo seus objetos de consumo, como shows, filmagens em andamento, entre outros (MASCARENHAS, 2017, p. 1).

Pode-se dizer que as fãs de Paula Pimenta, nessas peregrinações, somam três experiências distintas: (1) a viagem interna do fã, pela qual se deslocam simbolicamente para o ambiente ficcional; (2) a viagem física, quando visitam o local geográfico que serve de cenário para as histórias; (3) o diferencial de fazer a peregrinação junto com o próprio ídolo, estabelecendo contato direto com ele e, tal como apontado anteriormente, rompendo a barreira da sacralidade ao se relacionar de maneira próxima e desenvolver laços supostamente de amizade, ao menos durante a viagem.

Mascarenhas (2017) aponta que essas peregrinações, que inicialmente se davam de maneira mais "orgânica", como iniciativa dos próprios fãs, foram posteriormente apropriadas pelo mercado, que passou a oferecer produtos personalizados: "É uma tentativa da indústria do 
entretenimento de atribuir valor a esse tipo de experiência" (MASCARENHAS, 2017, p. 2).

\section{Celebridade e "consumo de experiência" no caso Paula Pimenta}

As reações observadas e as experiências relatadas pelas "pimentinhas" refletem, de forma especial, a construção dos laços simbólicos que se estabelecem, na sociedade moderna contemporânea, entre fãs e celebridades. A escritora Paula Pimenta, pondo-se à disposição de um mercado consumidor de literatura juvenil sem precedentes tanto no seu representativo volume quanto nas práticas incorporadas, torna-se objeto de estudo bastante elucidativo para os fins que aqui se colocam.

Destacaremos, a princípio, três pontos fundamentais: (1) a construção de sua subjetividade a partir de uma noção expandida de juventude; (2) a necessária aproximação com o público através da expressiva visibilidade midiática; (3) a disposição de um dado estilo de vida que pauta, de alguma forma, a construção da diferença e da identidade entre os jovens.

Considerando, portanto, o primeiro desses três aspectos, pode-se reconhecer em Paula Pimenta a confluência dos valores centrais da noção de juventude, conforme já se propôs anteriormente: aos 42 anos, a escritora constrói para si mesma uma identidade adolescente ao expressar, nas redes sociais digitais, suas preferências por bichos de pelúcia e parques temáticos, evidenciando-se a ambiguidade criança-adulto. Da mesma forma, assumindo-se que se trata de uma celebridade e, como tal, de uma fabricação cultural, Pimenta está presente em diferentes plataformas midiáticas, visibilizando uma fragmentação de si para fins comerciais. Além disso, ao dividir com sua legião de fãs o seu cotidiano, colocando-se como amiga, demonstra perceber a importância da afetividade nessa relação; seja através do produto de suas obras, seja pela própria forma como se coloca diante de um mundo adulto, mostra-se, de alguma maneira, "transgressora" e "questionadora". Como 
celebridade-mercadoria, reúne um conjunto de afinidades que acaba por agregar grupos plurais de jovens, seja no ambiente on-line ou off-line. Por fim, constituindo-se parte mesma da ideia basal de uma celebridade atribuída (ROJEK, 2008), é “autêntica” em seu cotidiano e experiências partilhadas através da enorme visibilidade midiática reivindicada nas diferentes redes sociais digitais que mantém.

Como consequência desse lugar privilegiado da comunicação que sustenta o primeiro ponto, apresenta-se o segundo: Paula Pimenta é celebridade, não estrela. Precisa romper, portanto, com a distância intransponível que separava os admiradores de suas atrizes de cinema divinizadas. Para tanto, se fotografa em seu quarto e compartilha sua vida publicamente; divide seus segredos e, mais, viaja com suas fãs; valoriza a aproximação, se esforça por se deixar tocar, tal qual, grosso modo, uma mercadoria em exposição; por outro lado, precisa manter a magia e a sedução, alimentando, através de suas ficções e das experiências vividas para além das páginas de seus livros, um sonho ou relações imaginárias que vão pautar aquilo que deve ser imitado por suas leitoras-fãs.

E esse é o terceiro e último aspecto que, entre outros possíveis, se destaca na análise de Paula Pimenta: como celebridade, compõe um estilo de vida particular, único, distinto, pronto para ser escolhido e imitado. O conjunto simbólico de valores e práticas presentes em sua aparência, no lugar onde vive, naquilo que expressa, nos seus gestos e na forma como se define, tudo isso representa uma escolha entre tantas possíveis para um público que, por definição, está em construção. O adolescente, como caracterizado nas diversas formas de representação social dessa fase da vida, é um ser inacabado e, portanto, precisa se diferenciar para se identificar. Celebridades como Paula Pimenta, que extrapolam as fronteiras midiáticas e se permitem explorar em outros ambientes de experimentação, na "vida real", acabam por se tornar âncoras muito atrativas em tempos de escassez e dissolução de ideologias, heróis e mitos.

Os laços entre as fãs e a escritora Paula Pimenta também podem ser pensados a partir de uma reflexão em torno do conceito de "consumo de 
experiência". O que seria, afinal, consumir uma "experiência”? Pode-se pensar, inicialmente, em um consumo que não implica a compra e posse de um bem, mas na fruição de um acontecimento-evento-experiência que envolve um alto engajamento emocional por parte do sujeito por se comunicar de forma profunda com o seu universo "cosmológico" particular. No contexto do "consumo de experiência”, não cabe a ideia de um indivíduo passivo, mas de um sujeito dinâmico que interage e interfere nas situações às quais é exposto.

Na discussão sobre esse conceito, destacamos dois autores que apresentam abordagens mais diretamente relacionadas aos fins do presente artigo: Colin Campbell (1987) e Laura Graziela Gomes (2007). Campbell (1987), ao buscar os caminhos que levaram à instituição do consumo moderno, apresenta o conceito de daydream, que se caracteriza pelo uso da imaginação visando ao prazer através da antecipação de um evento real. Os sonhos do daydream estão nos "limites" do real, mesmo quando são muito improváveis de acontecer; trata-se de introduzir no processo de imaginação uma antecipação prazerosa do futuro. Campbell (1987, p. 128) chama esse processo de "hedonismo autoilusório", no qual o indivíduo é o artista da imaginação e do sonho pegando imagens e as rearranjando como produtos únicos. Essa seria, a seu ver, uma legítima faculdade moderna - a de criar uma ilusão que se sabe falsa, mas que é sentida como verdadeira. Se a experiência do dia a dia não leva à diversão, surge com o daydream a possibilidade de escapar, buscando prazer no espaço da imaginação. Nesse "hedonismo num outro mundo", diferente do hedonismo tradicional, o desconhecido é um campo aberto para inúmeras e irrestritas possibilidades de prazer. O desejo, aqui, está alocado no desconhecido - o próprio desejo é uma atividade de prazer.

O trabalho de Gomes (2007), por sua vez, analisa fansites ligados a séries de TV norte-americanas, explorando diretamente o conceito de "consumo de experiência":

As fanarts são as manifestações concretas do que estou designando como "consumo da experiência" e, nesse caso, traduzem uma gama muito rica de formas e modos pelos quais a vivência e o consumo dessa experiência 
ocorrem pessoal e coletivamente nos fansites, já que há um investimento grande na sua produção. Não só elas envolvem o uso e o manejo de vários recursos e habilidades, desde a escrita (fanfictions), como até a utilização de softwares sofisticados para tratamento e manipulação digital de imagens (animações, vídeos etc.). Tudo isso feito em nome do amor que sentem pelas séries e suas personagens prediletas (GOMES, 2006, p. 8).

A autora destaca que, especialmente após o advento das novas mídias, o consumidor passa a ter acesso direto a conteúdos que lhe permitem experimentar, ressignificar - através das fanfics - e partilhar experiências relacionadas a seu universo ficcional de predileção. Essa possibilidade de manipulação envolve afetos resultantes de um forte engajamento emocional derivado da conexão criativa com paisagens imaginárias. Em um contexto cultural no qual a mídia tem uma centralidade nos termos de "instituir e patrocinar os rituais e os cultos aos heróis da vida cotidiana" (GOMES, 2006, p. 3), cabe investigar situações concretas em que o "consumo de experiência" aciona determinados estados de subjetividade na relação entre fãs e celebridades, como a analisada no presente artigo.

Gomes (2007), assim, mostra como as fanarts evidenciam o papel ativo dos fãs, que, através de intervenções criativas, reconstroem os universos ficcionais dos seus autores preferidos - questão também tratada por Jenkins (2009) dentro da ideia de "cultura participativa". O daydream (CAMPBELL, 1987), antes proporcionado apenas pela produção do autor, passa a ser criado também por parte do seu público, que produz e faz circular um imaginário ficcional agora expandido.

Na relação das fãs com Paula Pimenta, parece haver outra dinâmica atuando, inserida no contexto da cultura participativa. Um dos aspectos que mais chama atenção no caso analisado é a expansão do universo ficcional para a "vida real" a partir do momento em que surgem situações como a da viagem com a escritora, na qual as fãs circulam nos mesmos locais que os personagens dos livros, além de comemorar os aniversários de alguns deles como se fossem eventos reais, trazendo a dimensão do sonho para a "realidade". Campbell (1987) enfatiza em sua análise 
que o daydreaming tem seu encanto por ser formulado no campo da imaginação; sempre que algo desejado se tornasse real, provocaria um sentimento de frustração, porque a realidade nunca conseguiria se aproximar do prazer proporcionado pelo devaneio. No caso das fãs de Paula Pimenta, parece estar atuando um outro modelo, em que a fabulação penetra na "vida real". Os universos sonhados a partir da leitura dos livros passam a ser vivenciados por todos como um "fato" - como fazer as mesmas coisas que os personagens -, fazendo com que o daydreaming, assim, se materialize. Trata-se de uma experiência que se sabe parte do devaneio provocado pela imersão em universos ficcionais, mas que toma uma forma concreta através de uma experiência no campo do "real". Pelos relatos a respeito da viagem aos cenários das histórias, a experiência do daydreaming materializado, ao contrário de ser frustrante como propunha Campbell, acaba por manter e eternizar as fortes emoções já sentidas na leitura dos livros.

Pereira, Siciliano e Rocha (2015) propõem uma distinção entre o "consumo de experiência" e a "experiência de consumo", em que o primeiro promove uma suspensão da descrença e total imersão do sujeito em uma experiência que tem início, meio e fim, com uma narrativa previamente conhecida e que, entre outros aspectos, se diferencia da segunda principalmente por ter a experiência em si como o bem ou a coisa a ser consumida. Em outras palavras, todo consumo pressupõe uma experiência, porém nem toda experiência promove tal deslocamento do sujeito para um lugar outro que não o da realidade cotidiana.

Dentro do "consumo de experiência" vivenciado pelas fãs, a amizade e a proximidade com a autora chamam especial atenção. Os afetos, que já eram fortes com o universo ficcional de Paula, ganham maior voltagem no contato direto em que se realiza o sonho recorrente do fã de sair do anonimato e se diferenciar diante de seu ídolo. Como explica Maria Cláudia Coelho, trata-se da "[...] esperança do fã de ser correspondido nos sentimentos que nutre pelo ídolo, de quebrar aquela assimetria básica do relacionamento e de estabelecer uma relação de reciprocidade" (COELHO, 1999, p. 53). No caso, a experiência propicia um alto 
engajamento emocional porque a aura de amizade e de intimidade que permeia toda a viagem coloca o seleto grupo de fãs dentro de uma esfera de proximidade em que sentimentos são compartilhados, indicando um movimento em direção a uma maior reciprocidade na relação. Paula fica "amiga" das fãs, se emociona com a viagem tanto quanto elas e expressa nas redes sociais os sentimentos de saudades após o fim do intercâmbio. Percebe-se que a assimetria entre as fãs e a escritora diminui bastante, sem desaparecer, pois é a proximidade com a autora do universo ficcional que intensifica o encantamento da situação vivida. Além disso, há também a quebra da rotina e a experiência como bem a ser consumido, que mistura realidade e ficção, que se transporta das páginas do livro para as paisagens factualmente visitadas, transportando também as adolescentes para outro cotidiano, o das personagens, como Fani.

Pode-se remeter, neste ponto, à análise de Rocha (1995) em relação aos mundos de "dentro" e de "fora" dos meios de comunicação de massa. Ao se debruçar sobre o filme A rosa púrpura do Cairo, de Woody Allen - em que uma personagem humana (Cecília) consegue se infiltrar na história do filme a que assiste no cinema ao mesmo tempo que um personagem do "filme dentro do filme" (Tom Baxter) se "liberta" ao cruzar a tela que separa o filme da vida real -, o autor tematiza a fluidez de fronteiras entre a realidade e a ficção. Através da emoção da personagem Cecília, as barreiras entre os universos do produto midiático e da sociedade industrial que assiste ao filme desmoronam no momento em que ela "atravessa a tela" e passa a viver no mundo totêmico, abundante e mágico existente "dentro" dos meios de comunicação de massa.

As fãs de Paula, a seu modo, também têm acesso a essa visão "interna" dos meios de comunicação, em que as fronteiras entre ficção e realidade se mostram permeáveis. Nesse caso, é possível se pensar na ideia de "consumo de experiência" não apenas como a possibilidade de os fãs serem criadores de novos conteúdos a partir de um universo original, mas especialmente como um caminho em que o fã vê a si próprio inserido em uma narrativa expandida que mistura imaginação à experiência e às emoções daí decorrentes. 


\section{Considerações finais}

O artigo teve como objetivo, a partir de um estudo de caso da escritora Paula Pimenta, refletir sobre o fenômeno das celebridades e, de forma mais específica, sobre sua relação com a mídia e a construção de identidades juvenis contemporâneas. Nesse caminho, a ideia de "consumo de experiência” mostrou-se produtiva para pensar os afetos e estados de subjetividade vivenciados pelas fãs.

Analisando a escritora Paula Pimenta em determinadas relações com suas leitoras, foram destacados, entre outros pontos, a construção de sua subjetividade a partir de uma noção expandida de juventude e a necessária aproximação com o público através da expressiva visibilidade midiática.

Como visto, as fãs de Paula, como outros grupos no cenário midiático contemporâneo, expõem seus afetos vinculados ao universo da escritora, fazendo circular informações em plataformas digitais, escrevendo diários temáticos ou ainda interferindo no processo de editoração de sua obra.

No entanto, um determinado evento e seus desdobramentos inspiraram as reflexões deste artigo, a saber, as situações relacionadas à viagem da escritora com um grupo de fãs. Campbell (1987) argumenta que, no hedonismo moderno e autoilusivo, o sujeito é o "artista do sonho", que obtém prazer das emoções despertadas por imagens associadas a bens ou produtos midiáticos. No "consumo de experiência" analisado no artigo, é possível expandir o prazer provocado pela ficção para a vida real sem que haja um sentimento de desencanto, como afirmava o autor em relação aos mecanismos de concretização do daydreaming na vida cotidiana. Os universos sonhados a partir da leitura dos livros passam a ser vivenciados por todos como um "fato" ou, ainda, uma experiência que se sabe parte de um devaneio, mas que é materializada em uma experiência no campo do "real".

Victor Turner (2005), em um dos seus estudos sobre ritual, faz uma exploração etimológica da palavra "experiência" e chega a uma aproximação com a palavra "perigo", que teria o mesmo prefixo indo-europeu 
"per", evocando o significado de "tentar, aventurar-se, correr riscos". Destaca, ainda, seu caráter formador e transformador. Já em Campbell (1987), a experiência do consumo aparece como um momento de frustração, quando se revela menos prazerosa que os sentimentos do daydreaming. No caso analisado no artigo, a dimensão da experiência contorna possíveis sentimentos de perigo e frustração, configurando-se como uma espécie de "realidade mágica" onde afetos permeiam os laços cada vez mais estreitados entre fãs, escritora e personagens do universo ficcional.

\section{Referências}

BOORSTIN, D. J. From hero to celebrity: the human pseudo-event. In: MARSHALL, P. D. (Org.). The celebrity culture reader. Nova York: Routledge, 2006. p. 72-90.

CAMPBELL, C. The romantic ethic and the spirit of modern consumerism. Oxford: Blackwell Publishers, 1987.

COELHO, M. C. A experiência da fama: individualismo e comunicação de massa. Rio de Janeiro: FGV, 1999.

FRITZSCHE, B. Negociando o feminismo pop na cultura jovem feminina: um estudo empírico com fãs de grupos femininos. Estudos Feministas, Florianópolis, v. 12, n. 2, p. 106-115, maio-ago. 2004.

GABLER, N. Vida, o filme: como o entretenimento conquistou a realidade. São Paulo: Companhia das Letras, 1999.

GIDDENS, A. Modernidade e identidade. Rio de Janeiro: Zahar, 2002.

GOMES, L. G. Fansites ou o "consumo da experiência” na mídia contemporânea. Horizontes antropológicos, v. 13, n. 28, 2007.

JENKINS, H. Cultura da convergência. São Paulo: Aleph, 2009.

MASCARENHAS, A. M. A peregrinação do fã e comodificação de memórias em Las Vegas. In: ENCONTRO NACIONAL DE PESQUISADORES EM PUBLICIDADE E PROPAGANDA (PROPESQ), VIII, 2017, Recife. Anais... Recife: UFPE, 2017. Disponível em: http://docs.wixstatic.com/ugd/bb9c7e_7fb21233b28e464cb3710aa7a52e 2d55.pdf. Acesso em: 8 jan. 2018.

MAUSS, M. Sociologia e antropologia. São Paulo: EdUSP, 1974.

MCROBBIE, A.; GARBER, J. Girls and subcultures. In: HALL, S.; JEFFERSON, T.

(Orgs.). Resistance Through Rituals. Youth subcultures in post-war Britain. Londres: 
Hutchinson; Birmingham: The Center of Contemporary Cultural Studies from the University of Birmingham, 1975. p. 209-222.

MILLER, D.; SLATER, D. Etnografia on e off-line: cibercafés em Trinidad. Horizontes antropológicos, Porto Alegre, ano 10, n. 21, p. 41-65, jan.-jun. 2004.

MORIN, E. Estrelas: mito e sedução no cinema. Rio de Janeiro: José Olympio, 1989.

ORGAD, S. How can researchers make sense of the issues involved in collecting and interpreting online and offline data? In: MARKHAM, A.; BAYMN, N. (Eds.). Internet inquiry. Conversations about method. Los Angeles: Sage, 2009. p. 33-53.

PEREIRA, C.; SICILIANO, T.; ROCHA, E. "Consumo de experiência” e "experiência de consumo”: uma discussão conceitual. Logos, v. 22, n. 2, p. 6-17, 2015.

PIMENTA, P. Blog Fazendo meu Filme. Disponível em: http://blogfazendomeufilme. blogspot.com.br/search/label/intercâmbio. Acesso em: 11 ago. 2017.

. Fazendo meu filme. Belo Horizonte: Gutemberg, 2009.

. Fazendo meu filme 2. Belo Horizonte: Gutemberg, 2009.

. Fazendo meu filme 3. Belo Horizonte: Gutemberg, 2010.

Fazendo meu filme 4. Belo Horizonte: Gutemberg, 2012.

. Minha vida fora de série - $1^{\mathrm{a}}$ temporada. Belo Horizonte: Gutemberg, 2011.

Minha vida fora de série - $2^{a}$ temporada. Belo Horizonte: Gutemberg, 2013.

Minha vida fora de série - $3^{\mathrm{a}}$ temporada. Belo Horizonte: Gutemberg, 2015.

ROCHA, E. A sociedade do sonho: comunicação, cultura e consumo. Rio de Janeiro: Mauad X, 1995.

.; PEREIRA, C. Juventude e consumo: um estudo sobre comunicação na cultura contemporânea. Rio de Janeiro: Mauad X, 2009.

ROJEK, C. Celebridade. Rio de Janeiro: Rocco, 2008.

TURNER, V. Dewey, Dilthey e drama: um ensaio em antropologia da experiência.

Cadernos de Campo, n. 13, p. 177-185, 2005.

WOODWARD, K. Identidade e diferença: uma introdução teórica e conceitual. In: SILVA, T. T. da; WOODWARD, K.; HALL, S. Identidade e diferença. Petrópolis: Vozes, 2005. p. 7-72.

YIN, R. Estudo de caso - planejamento e métodos. Porto Alegre: Bookman, 2001.

\section{Sobre as autoras}

Marcella Azevedo - Doutoranda e mestre pelo Programa de Pós-graduação em Comunicação da PUC-Rio.

Cláudia Pereira - Professora adjunta do Programa de Pós-graduação em Comunicação da PUC-Rio. Doutora em Antropologia (PPGSA/IFCS/UFRJ). 
96 SUJEITO, Mídia E “CONSUMO DE EXPERIÊNCIA” NAS CELEbridADES JUVENIS

Carla Barros - Professora do Programa de Pós-graduação em Comunicação Social da UFF. Doutora em Administração pelo Coppead/UFRJ na área de Antropologia do Consumo.

Data de submissão: 28/08/2017

Data de aceite: 02/02/2018 